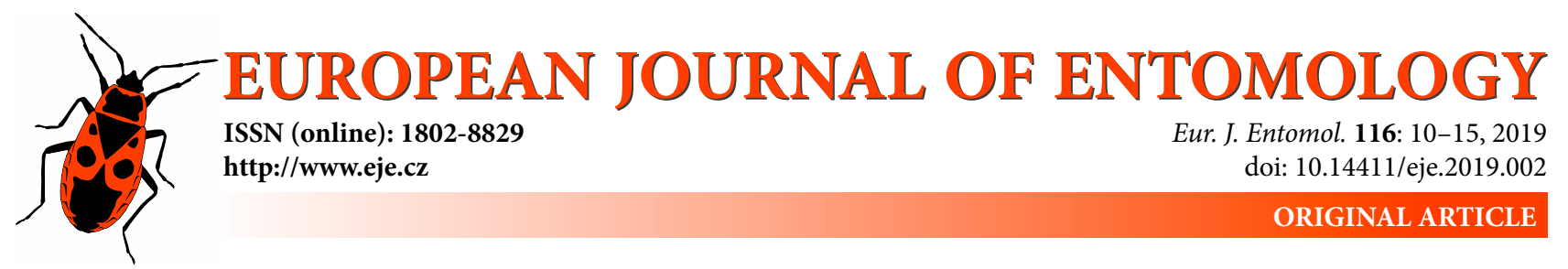

\title{
Effect of low-temperature storage on the life history parameters and voracity of Hippodamia variegata (Coleoptera: Coccinellidae)
}

\author{
Samane SAKAKI ${ }^{1}$, Mohammad Amin JALALI ${ }^{1, *}$, Hashem KAMALI ${ }^{2}$ and OLdř́lch NEDVĚD ${ }^{3,4}$ \\ ${ }^{1}$ Department of Plant Protection, College of Agriculture, Vali-e-Asr University of Rafsanjan, Rafsanjan, Iran; \\ e-mails: ma.jalali@vru.ac.ir; sama.sakaki65@gmail.com \\ 2 Plant Protection Research Department, Khorasan Razavi Agricultural and Natural Resources Research and Education Center, \\ AREEO, Mashhad, Iran; e-mail: hashemkamali@gmail.com \\ ${ }^{3}$ Faculty of Science, University of South Bohemia, Branisovska 31, 37005 Ceske Budejovice, Czech Republic; \\ e-mail: nedved@prf.jcu.cz \\ ${ }^{4}$ Institute of Entomology, Academy of Sciences of the Czech Republic, Branisovska 31, 37005 Ceske Budejovice, Czech \\ Republic
}

Key words. Coleoptera, Coccinellidae, Hippodamia variegata, cold tolerance, chilling, fertility, ladybird, shelf-life, voracity, predation capacity

\begin{abstract}
For biological control it is necessary to store mass-reared biological control agents when the demand is low. The objective of this study is to increase their shelf life without significantly reducing their fitness. The ladybird Hippodamia variegata is a widespread and voracious aphidophagous predator, with an important role in decreasing the abundance of pest aphids in many parts of the world. We investigated the effect of storage at three temperatures: constant $1^{\circ} \mathrm{C}$, constant $6^{\circ} \mathrm{C}$, and an alternating thermal regime of $12^{\circ} \mathrm{C} / 0^{\circ} \mathrm{C}$ (the higher temperature for $12 \mathrm{~h}$ and the lower one for another $12 \mathrm{~h}$ ). They were exposed to each of the temperature regimes for either $15,25,35,45$ or 60 days. We recorded survival, pre-oviposition period, fecundity and voracity of adult $H$. variegata following storage. The survival of adult beetles significantly declined with increasing storage duration at all three temperatures. Storage at $6^{\circ} \mathrm{C}$ up to 35 days and at $12^{\circ} \mathrm{C} / 0^{\circ} \mathrm{C}$ up to 45 days had no significant effects on the fecundity of the ladybirds, but storage for longer significantly decreased fecundity. Beetles stored at $1^{\circ} \mathrm{C}$ for any of the durations had significantly lower fecundities. Prolonged cold storage caused an increase in the pre-oviposition period at all storage temperatures. Generally, $6^{\circ} \mathrm{C}$ and $12^{\circ} \mathrm{C} / 0^{\circ} \mathrm{C}$ are the best temperatures for storing the ladybirds as they had the least negative effect on their fitness. The results of this research can help in improving the quality of $H$. variegata stored for use as biological control agents in the following season.
\end{abstract}

\section{INTRODUCTION}

For biological control programs it is necessary to mass produce beneficial insects. The major difficulty in achieving a successful mass release is the availability of high numbers of beneficial insects and the cost of producing these agents (Colinet \& Boivin, 2011). Most of the insects used in biological control programs have a shorter shelflife than pesticides, so they need to be produced shortly before they are released. Storage of biological control agents at low temperature is used to increase their shelf-life and provide a constant supply (McDonald \& Kok, 1990; Venkatesan et al., 2000), which can be utilized whenever there is a pest outbreak (Pitcher et al., 2002; Colinet \& Boivin, 2011). Cold storage of insects is also used in sterile insect technique programs (SIT), keeping pollinators (Rinehart et al., 2013), colony maintenance in the laboratory for re- search, pet food and to rescue endangered species (Leopold, 2007). However, the influence of cold storage on the efficacy of predators is poorly investigated.

Following cold storage, increase in mortality decreases the effectivity of biocontrol insects. Less apparent are the sublethal effects of storage. Lady beetles in the temperate climatic zone overwinter as adults and those of Coccinella undecimpunctata survive better than the other developmental stages (Abdel-Salam \& Abdel-Baky, 2000). Storage of second and third instar larvae of Coleomegilla maculata for two weeks at 4 and $8{ }^{\circ} \mathrm{C}$ results in almost $100 \%$ survival (Gagné \& Coderre, 2001). More than $80 \%$ of Harmonia axyridis adults survive 150 days at $3^{\circ} \mathrm{C}$ and $6^{\circ} \mathrm{C}$ (Ruan et al., 2012).

Sublethal effects of prolonged storage include delayed oviposition, lower fecundity and fertility and lower voraci-

\footnotetext{
* Corresponding author; e-mail: ma.jalali@vru.ac.ir
} 
ty, but these effects on predators are rarely quantified. Cold storage of Harmonia axyridis for several months have no adverse effect on fecundity (Ruan et al., 2012; Awad et al., 2013).

The ladybird Hippodamia variegata is an aphidophagous predator that is native and widespread in the Palearctic and occurs in some Nearctic areas (Obrycki \& Orr, 1990) and has been introduced into South America, South Africa and Australia (Franzmann, 2002). In Europe, it is a widespread species (Hodek \& Honek, 1996) and important predator of aphid pests in some countries such as Bulgaria, Italy, Ukraine, Greece, Turkmenistan and India (Kavallieratos et al., 2002; Kontodimas \& Stathas, 2005). It is also widespread in Iran where it usually has 2-3 generations every year (Koohpayezadeh \& Mossadegh 1991; Yaghmaee \& Kharazi Pakdel, 1995; Jalali et al., 2014). Under suitable conditions of temperature and food supply, this coccinellid is active throughout the year, otherwise, it overwinters as an adult (Loch, 2004).

Regarding the effect of cold storage, there is only one study on the survival of overwintering adults of $H$. variegata (Hamedi \& Moharramipour, 2013). Hence, due to the important role of this predator in suppressing aphid populations, more studies on the effects of cold storage on the efficacy of this lady beetle are needed.

In this research, we investigated the lethal and sublethal effects of low temperature on a biocontrol agent, adults of the ladybird $H$. variegata. We did this by determining the temperature and duration of storage that had the least adverse effect on adult $H$. variegata in terms of survival, preoviposition duration, fecundity and voracity.

Because temperature fluctuates cyclically in nature, it is important to measure survival at both constant and fluctuating temperatures, above or below $0^{\circ} \mathrm{C}$ (Bale, 1989; Rinehart et al., 2013). Fluctuating temperatures within the range favourable for development usually improve subsequent performance of cooled insects (Colinet et al., 2015). Therefore, in this research, we also compare the effect of two low-constant temperatures to one fluctuating thermal regime (FTR).

\section{MATERIALS AND METHODS}

\section{Rearing of prey and predator}

Adult $H$. variegata were collected from alfalfa and wheat farms at the Khorasan Razavi Agricultural and Natural Resources Research and Education Centre $\left(36^{\circ} 18^{\prime} \mathrm{N}, 59^{\circ} 36^{\prime} \mathrm{E}\right)$. These adults were transferred to a laboratory and reared for two generations under diapause suppressing conditions: $25^{\circ} \mathrm{C}, 65 \pm 5 \% \mathrm{RH}$ and a photoperiod of $16 \mathrm{~L}: 8 \mathrm{D}$, and fed aphids. Cotton aphids, Aphis gossypii, were reared on cucumber plants (Cucumis sativus) in 20 $\mathrm{cm}$ diameter pots at $23^{\circ} \mathrm{C}, 65 \pm 5 \% \mathrm{RH}$ and a photoperiod of $16 \mathrm{~L}$ : $8 \mathrm{D}$. The aphid colony was reared for ten generations before being used in the experiments.

\section{Survival}

Following emergence, adult ladybirds were kept in diapause inducing conditions: $20^{\circ} \mathrm{C}, 65 \pm 5 \% \mathrm{RH}$ and $12 \mathrm{~L}: 12 \mathrm{D}$ for two weeks, and then at $15^{\circ} \mathrm{C}, 65 \pm 5 \% \mathrm{RH}$ and $12 \mathrm{~L}: 12 \mathrm{D}$ for two weeks to further induce diapause prior to cold storage. Then they were exposed to one of three experimental temperature regimes
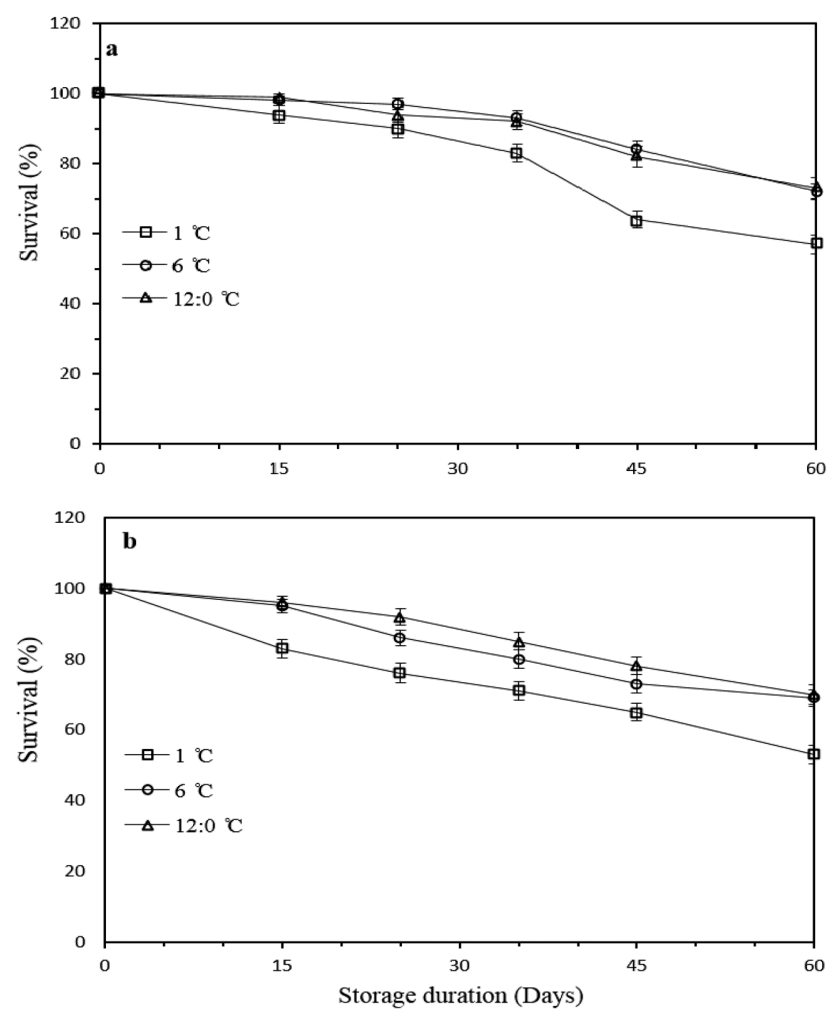

Fig. 1. Percentage survival (mean $\pm \mathrm{SE}$ ) of adult $H$. variegata stored for different durations at different temperatures. a - females; b - males.

for different periods of time. The cold storage was at one of two constant temperatures: $1^{\circ} \mathrm{C}$ or $6^{\circ} \mathrm{C}$ and one fluctuating thermal regime (FTR): $12^{\circ} \mathrm{C} / 0^{\circ} \mathrm{C}\left(12^{\circ} \mathrm{C}\right.$ and $0^{\circ} \mathrm{C}$ alternating every $\left.12 \mathrm{~h}\right)$ in transparent plastic boxes $(13 \times 15 \times 3 \mathrm{~cm})$ in the dark. They were stored for either $15,25,35,45$ or 60 days.

One hundred transparent plastic boxes, each with 5 males and a 100 with 5 females were kept at each storage temperature. Forty plastic boxes (i.e. 20 with 100 females and 20 with 100 males) were randomly taken out of storage, using a lottery system, after every storage duration and transferred to the activation regime: $25 \pm 1{ }^{\circ} \mathrm{C}, 65 \pm 5 \% \mathrm{RH}$ and photoperiod of $16 \mathrm{~L}: 8 \mathrm{D}$. After $24 \mathrm{~h}$ in the activation regime, adults were observed and recorded as alive if they were able to move (walk). We calculated the percentage survival for each small (5 individuals) group and the average and standard error (Fig. 1) for each treatment.

\section{Fecundity and pre-oviposition period}

After cold storage and the activation regime, which resembles the conditions under which the beetles will be released in biocontrol programs $\left(25^{\circ} \mathrm{C}, 65 \pm 5 \% \mathrm{RH}\right.$ and $16 \mathrm{~L}: 8 \mathrm{D}=$ control insects), the $H$. variegata laid eggs. Females and males that were stored at the same temperature and for the same period of time were used to assemble 10-13 pairs (each female mated with a single male) per treatment (combination of temperature and time) in individual transparent plastic boxes $(13 \times 15 \times 3 \mathrm{~cm})$. Each pair was fed daily with about 120 cotton aphids on a cucumber leaf. Pre-oviposition period starting from the day they were removed from cold storage was recorded. The number of eggs laid was recorded every $24 \mathrm{~h}$ and the adults transferred to new boxes with prey until the death of the female. The standard non-diapause inducing conditions $\left(25 \pm 1^{\circ} \mathrm{C}, 65 \pm 5 \% \mathrm{RH}\right.$, and $\left.16 \mathrm{~L}: 8 \mathrm{D}\right)$ were used during this experiment. 

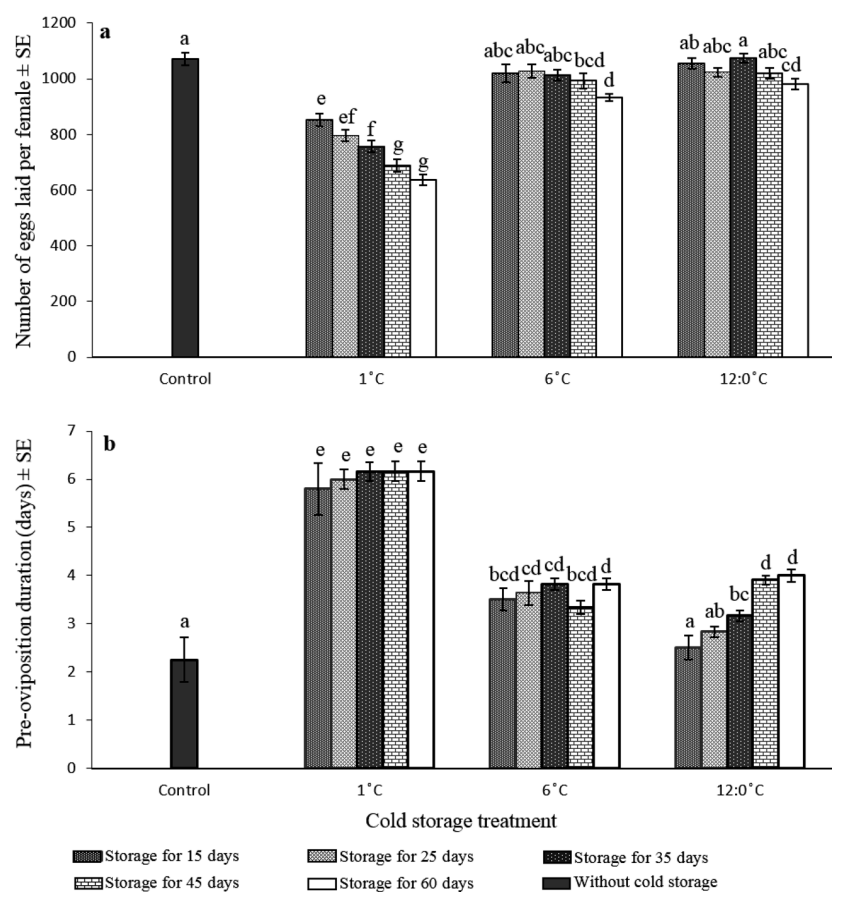

Fig. 2. Average fecundity (a) and pre-oviposition period (b) (mean \pm SE) of $H$. variegata females subjected to different cold storage treatments. Different letters above the bars indicate significant differences (glht utility in R).

\section{Voracity}

The voracity of adults of $H$. variegata after cold storage was investigated. For this experiment, adults ( 20 males and 20 females) that had spent 25 days at one of the two storage temperatures and then in the activation regime were transferred to individual transparent plastic boxes $(13 \times 15 \times 3 \mathrm{~cm})$ with 120 third instar nymphs of $A$. gossypii feeding on detached leaves of cucumber. The total number of aphids killed by the beetle was recorded every $24 \mathrm{~h}$ and the beetles were transferred to new boxes with 120 of aphids. This procedure continued for 15 days. The standard non-diapause conditions $\left(25 \pm 1{ }^{\circ} \mathrm{C}, 65 \pm 5 \%\right.$ R.H. and $16 \mathrm{~L}$ : $8 \mathrm{D})$ were used during this experiment.

\section{Statistical analysis}

Distribution fitting function in Statistica software version 13 (Dell, 2016) indicated that the data for fecundity $\left(\chi^{2}=32.19\right.$, df $=10, \mathrm{p}=0.00037)$, pre-oviposition period $\left(\chi^{2}=278, \mathrm{df}=9, \mathrm{p}<\right.$ $0.00001)$ and survival $\left(\chi^{2}=388, \mathrm{df}=6, \mathrm{p}<0.00001\right)$ were not normally distributed, while that for voracity was almost normally distributed $\left(\chi^{2}=14.29, \mathrm{df}=7, \mathrm{p}=0.046\right)$. The Levene's test for homogeneity of variances did not reveal a significant deviance for fecundity $(\mathrm{F}=1.06, \mathrm{df}=14,158, \mathrm{p}=0.40)$ and voracity $(\mathrm{F}=2.45$, $\mathrm{df}=3,78, \mathrm{p}=0.070$ ), but for pre-oviposition period a highly significant deviation $(\mathrm{F}=4.61, \mathrm{df}=14,158, \mathrm{p}=0.000001)$. A one-way analysis of variance (ANOVA) was thus only used to compare the voracity of the $H$. variegata that were stored under different conditions.

General linear models with "quasi” distribution (link: identity) were performed for the fecundity, pre-oviposition period and survival using $\mathrm{R}$ software. We used the glm and anova utility for analysing the two factors (storage temperature and duration) with interaction. Then we used the glht utility from multcom package for post-hoc comparison of all combinations of treatments.

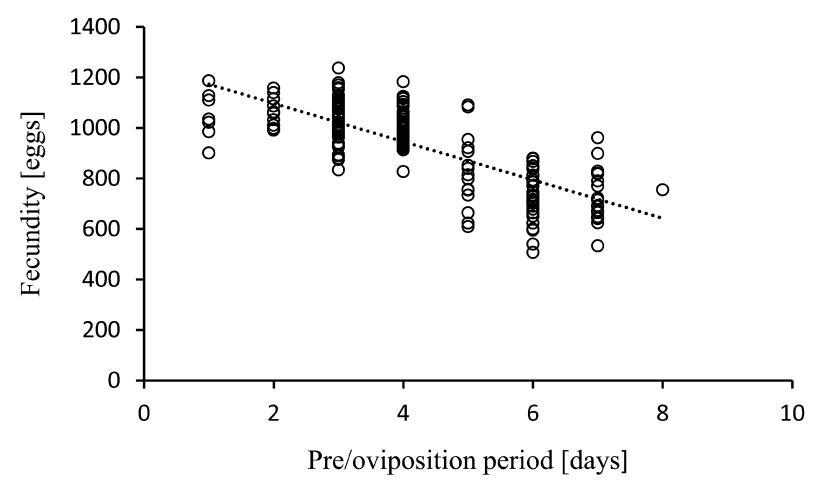

Fig. 3. Relationship between fecundity and pre-oviposition period for all of the females of $H$. variegata that survived the different storage treatments.

Linear regression of the relationship between fecundity and pre-oviposition period was computed in Statistica 13 (TIBCO Software Inc., 2017).

\section{RESULTS}

\section{Survival of cold storage}

Significant differences in adult survival were recorded among the different storage temperature conditions $\left(1^{\circ} \mathrm{C}\right.$, $6^{\circ} \mathrm{C}, 12^{\circ} \mathrm{C} / 0^{\circ} \mathrm{C}$ ) (Females: $\mathrm{F}_{2,285}=39, \mathrm{P}<0.0001$; Males: $\mathrm{F}_{2,285}=54, \mathrm{P}<0.0001$ ) and storage durations (Females: $\mathrm{F}_{4}$, ${ }_{285}=89, \mathrm{P}<0.0001$; Males: $\left.\mathrm{F}_{4,285}=58, \mathrm{P}<0.0001\right)$, and the interaction storage temperature $\times$ duration had little or no effect on survival (Females: $\mathrm{F}_{8,285}=2.45, \mathrm{P}=0.011$; Males: $\left.\mathrm{F}_{8,285}=0.42, \mathrm{P}=0.89\right)$.

Increasing storage duration resulted in a decrease in survival of both females and males (Fig. 1a and b). The female and male survival decreased markedly (to 55-57\%) after 60 days of storage at $1^{\circ} \mathrm{C}$. More than $90 \%$ of the females survived for 35 days at both $6^{\circ} \mathrm{C}$ and $12^{\circ} \mathrm{C} / 0^{\circ} \mathrm{C}$, but then survival decreased significantly the longer they were stored.

\section{Fecundity and pre-oviposition period after cold storage}

GLM model for the fecundity of $H$. variegata females explained $81 \%$ of the variance. Fecundity varied significantly among storage temperature treatments $\left(\mathrm{F}_{2,169}=290\right.$, $\left.\mathrm{P}=2 \cdot 10^{-16}\right)$ and storage durations $\left(\mathrm{F}_{4,165}=15.5, \mathrm{P}=10^{-10}\right)$; and also, the interaction storage temperature $\times$ duration had a small but significant effect on fecundity $\left(\mathrm{F}_{8,157}=\right.$ $2.51, \mathrm{P}=0.013$ ) (Fig. 2a). Similarly, pre-oviposition duration (variance explained by model $=79 \%$ ) differed significantly among storage temperature treatments $\left(\mathrm{F}_{2,169}=278\right.$, $\left.\mathrm{P}=2 \cdot 10^{-16}\right)$ and storage durations $\left(\mathrm{F}_{4,165}=7.07, \mathrm{P}=3 \cdot 10^{-5}\right)$; and the interaction storage temperature $\times$ duration was also significant $\left(\mathrm{F}_{8,157}=2.72, \mathrm{P}=0.008\right)$ (Fig. 2b).

Storage of adult $H$. variegata for 35 days at $6^{\circ} \mathrm{C}$ and 45 days at $12^{\circ} \mathrm{C} / 0^{\circ} \mathrm{C}$ had no significant effect on their fecundity. After being stored longer, fecundity decreased significantly in comparison to control insects and those stored for shorter periods. Fecundity of beetles that were stored at $1^{\circ} \mathrm{C}$ was significantly lower than that of control beetles and 


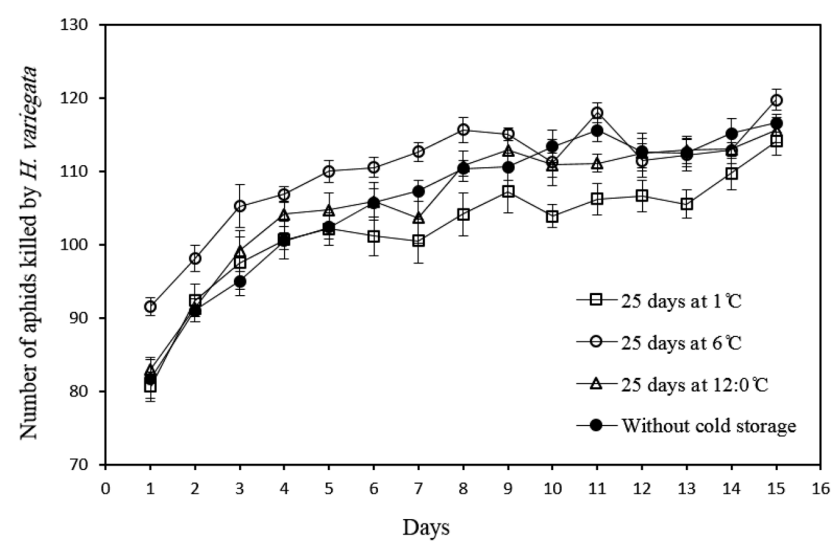

Fig. 4. Number of aphids killed (mean \pm SE during 15 days of observation) by all of the adult pairs of $H$. variegata that survived storage for 25 days in the different storage treatments.

those stored at the two higher temperatures for all storage durations.

The storage for 25 days at $12^{\circ} \mathrm{C} / 0^{\circ} \mathrm{C}$ had no significant effect on the pre-oviposition period. It then increased with increase in storage duration. At $6^{\circ} \mathrm{C}$, the pre-oviposition period was slightly longer than that of the control, even after the shortest duration. The longest pre-oviposition periods were recorded after storage for 60 days at both $6^{\circ} \mathrm{C}$ and $12^{\circ} \mathrm{C} / 0^{\circ} \mathrm{C}$. At $1{ }^{\circ} \mathrm{C}$, the pre-oviposition period was much longer than at the two higher temperatures and the control, but did not change over time.

There was a close negative correlation between the duration of the pre-oviposition period and fecundity when the results for all the treatments were pooled (linear regression: $\mathrm{t}_{183}=-16 ; \mathrm{p}<10^{-6}$; Fig. 3).

\section{Voracity}

Number of aphids eaten in the different treatments differed $\left(\mathrm{F}_{3,57}=13.53, \mathrm{P}<0.0001\right)$, increased during the first five days of feeding and then reached equilibrium (Fig. 4). The adult pairs stored at $6^{\circ} \mathrm{C}$ consumed more aphids than the control beetles. Those that were stored at $12^{\circ} \mathrm{C} / 0^{\circ} \mathrm{C}$ consumed a similar number of aphids to the control adults and pairs stored at $1{ }^{\circ} \mathrm{C}$ consumed fewer aphids than the control beetles.

\section{DISCUSSION}

\section{Survival}

The results of our research demonstrate that storage at low temperature for a long time had both lethal and nonlethal effects on adult $H$. variegata.

\section{Storage temperature}

It is well known that survival at low temperatures is timeand temperature-dependent (Nedvěd, 1998; Renault et al., 2004). When planning the experiments, we decided to use low constant temperatures, which should decrease ageing and depletion of energetic reserves during storage (Colinet et al., 2006). Even keeping overwintering ladybirds at the higher acclimation/storage temperature of $10^{\circ} \mathrm{C}$ for 30 days used by (Hamedi \& Moharramipour, 2013), results in more than $80 \%$ mortality, probably due to depletion of energy reserves.

We also kept them in an alternating temperature regime in which the higher temperature may enable them to repair injuries caused by the lower temperature as is reported for other beetles (Renault et al., 2004).

H. variegata is a freeze intolerant species that cannot survive temperatures below their super cooling point (SCP). Exposure of pre-diapausing (October) H.variegata to $-3^{\circ} \mathrm{C}$ for 30 days (Hamedi \& Moharramipour, 2013) results in $75 \%$ mortality as at this stage in their development they are not very tolerant of cold. Fifteen percent of the overwintering adults collected from December to February died, and the least mortality was recorded for beetles collected in January, the coldest month. Moreover, none of the adults collected in December, January and February that are acclimated at $0^{\circ} \mathrm{C}$ for 30 days prior to exposure to lower temperature die (Hamedi \& Moharramipour, 2013).

In our study, the adults were only exposed to diapause inducing conditions for a short period and, therefore, not fully cold acclimated. Long exposure to diapause inducing conditions and gradual cold acclimation per se could result in some mortality and make storage more costly. We exposed the beetles to $1^{\circ} \mathrm{C}$ for 35 days resulting in $20-25 \%$ mortality. Storage at the higher temperature $\left(6^{\circ} \mathrm{C}\right)$, resulted in a mortality of only $7-15 \%$, which makes it practical to store this biocontrol agent.

\section{Duration of storage}

Regarding the length of exposure, we used durations of up to 60 days, which are often required in biocontrol practice for storing predators. In these practice-oriented conditions, survival of adult lady beetles $H$. variegata was $70 \%$ in the milder regimes (constant $6^{\circ} \mathrm{C}$ and fluctuating thermal regime (FTR) $12^{\circ} \mathrm{C} / 0^{\circ} \mathrm{C}$ ) and less than $60 \%$ in the coldest regime $\left(1^{\circ} \mathrm{C}\right)$. This is worse than the level of mortality reported for other adult lady beetles, such as $H$. axyridis, in which more than $80 \%$ survived after 150 days at $3^{\circ} \mathrm{C}$ and $6^{\circ} \mathrm{C}$ (Ruan et al., 2012). This could be due to their larger body size, since there are positive correlations between body size, lipid content and ability to tolerate low temperatures (Renault et al., 2003; Liu et al., 2007).

The survival of males decreased linearly with increase in the length of the period they were stored in all of the temperature conditions, while in females, there was very good survival up to 35 days and then a decrease after 45 days, which was used to define the storage duration of 40 days recommended for practical use.

\section{Pre-oviposition period}

The storage of $H$. variegata at low temperatures had sublethal effects. Storage at the low temperature resulted in a longer pre-oviposition period and lower fecundity than recorded at either the constant or fluctuating higher temperatures.

While the duration of storage at $6^{\circ} \mathrm{C}$ had no effect on the pre-oviposition period, increasing the storage duration at FTR $\left(12^{\circ} \mathrm{C} / 0^{\circ} \mathrm{C}\right.$, which has a mean of $\left.6^{\circ} \mathrm{C}\right)$ resulted in a gradual increase in the pre-oviposition period. This is at- 
tributed to an intensification of recently induced diapause (cf. Kostal \& Simek, 2000). As occurred in H. variegata, the duration of the pre-oviposition period in the subtropical Cryptolaemus montrouzieri also increases with increase in the duration of storage (Özgökçe et al., 2006).

\section{Fecundity}

As the fecundity of $H$. variegata was significantly decreased by storage at $1^{\circ} \mathrm{C}$ it is obvious that this temperature is not suitable for the long term storage of this beetle. For other temperatures $\left(6\right.$ and $\left.12^{\circ} \mathrm{C} / 0^{\circ} \mathrm{C}\right)$, fecundity was not affected until after 35 and 45 days in storage, respectively. After longer durations, the decrease in fecundity was statistically significant but acceptable for practical purposes. In contrast, the subtropical lady beetle $C$. montrouzieri is significantly less fecund even after storage at $15^{\circ} \mathrm{C}$ for 20 days (Özgökçe et al., 2006). On the other hand, there is no significant decrease in the fecundity of temperate (both Czech and Chinese) populations of $H$. axyridis after 5 and 6 months of cold storage (but here is an earlier decrease in fertility), respectively (Ruan et al., 2012; Awad et al., 2013). This confirms the superiority of this successful invasive species.

As there was a non-linear decrease in lifetime fecundity with the delay in the onset of oviposition (main decrease in fecundity occurred between pre-oviposition duration 4 and 5 days), it is likely that there is a threshold in the level of cold injury that results in both life history parameters being adversely affected. The magnitude of the decrease in fecundity (from almost 1100 to almost 700 eggs) cannot be explained in terms of the delay in the onset of egg laying, but is more likely to be a sublethal effect of cold storage.

\section{Voracity}

Storage of adults of $H$. variegata at $6^{\circ} \mathrm{C}$ for 25 days resulted in them consuming more aphids than the control insects and had no negative effects on their life history parameters. Number of aphids consumed by beetles stored at $12^{\circ} \mathrm{C} / 0^{\circ} \mathrm{C}$ were similar that of the control beetles. Low temperature storage $\left(1^{\circ} \mathrm{C}\right)$ resulted in a lower voracity and had adverse effects on their life history parameters. Since voracity increased during the first 5-7 days after adult emergence in all treatments, we recommend a longer experimental duration when evaluating these characteristics. Comparable results exist for $H$. axyridis stored at $3^{\circ} \mathrm{C}$ for 150 days, which also consumed more aphids than the control beetles (Ruan et al., 2012). In terms of voracity, storage for durations of up to 60 days at $6^{\circ} \mathrm{C}$ is acceptable.

\section{CONCLUSION}

Adults of $H$. variegata can be stored for 35 and 45 days at a constant moderately low temperature and FTR, respectively, without reducing their fecundity. In addition, the pre-oviposition period did not increase after 25 days spent in the FTR, whereas a longer pre-oviposition period was recorded after the shortest period of storage at the constant moderately low temperature. The level of voracity was unchanged by the FTR and was even higher after storage at the moderately low temperature. Thus, both a constant moderate low temperature and fluctuating thermal regime with a similar average as the constant temperature are similarly suitable for the cold storage of adult $H$. variegata.

The results of this research can be used to improve the maintenance of laboratory and mass-reared colonies of the ladybird $H$. variegata. Although cold storage did not have a negative effect on the fecundity and voracity of adult $H$. variegata in the laboratory, field experiments are necessary to determine whether these artificially produced ladybirds are effective biocontrol agents.

ACKNOWLEDGEMENTS. We thank Vali-e-Asr University of Rafsanjan for financial support to S. Sakaki ( $\mathrm{PhD}$ student no. 92351002) and Khorasan Razavi Agricultural and Natural Resources Research and Education Center, AREEO, Mashhad, for providing the laboratory facilities. We also thank to the reviewers for insisting on a better analysis of our data and to J. Riegert for performing the statistical analysis in $\mathrm{R}$.

\section{REFERENCES}

Abdel-Salam A.H. \& AbDEl-Baky N.F. 2000: Possible storage of Coccinella undecimpunctata (Col., Coccinellidae) under low temperature and its effect on some biological characteristics. - J. Appl. Entomol. 124: 169-176.

Awad M., Kalushkov P., Nedvedova T. \& Nedved O. 2013: Fecundity and fertility of ladybird beetle Harmonia axyridis after prolonged cold storage. - BioControl 58: 657-666.

BALE J.S. 1989: Cold-hardiness and overwintering insects. Agric. Zool. Rev. 3: 157-192.

Colinet H. \& Borvin G. 2011: Insect parasitoids cold storage: A comprehensive review of factors of variability and consequences. - Biol. Contr. 58: 83-95.

Colinet H., Hance T. \& Vernon P. 2006: Water relations, fat reserves, survival, and longevity of a cold-exposed parasitic wasp Aphidius colemani (Hymenoptera: Aphidiinae). - Environ. Entomol. 35: 228-236.

Colinet H., Sinclair B.J., Vernon P. \& Renault D. 2015: Insects in fluctuating thermal environments. - Annu. Rev. Entomol. 60: $123-140$.

Franzmann B.A. 2002: Hippodamia variegata (Goeze) (Coleoptera: Coccinellidae), a predacious ladybird new in Australia. - Aust. J. Entomol. 41: 375-377.

GAGNÉ I. \& CoDerre D. 2001: Cold storage of Coleomegilla maculata larvae. - Biocontr. Sci. Technol. 11: 361-369.

HAmedi N. \& Moharramipour S. 2013: Long-term cold response in overwintering adults of ladybird Hippodamia variegata (Coleoptera: Coccinellidae). - J. Crop. Prot. 2: 119-126.

Hodek I. \& Honek A. 1996: Ecology of Coccinellidae. Kluwer Academic Publishers, Dordrecht, 464 pp.

Jalali M.A., Mehrnejad M.R. \& Kontodimas D.C. 2014: Temperature-dependent development of the five psyllophagous ladybird predators of Agonoscena pistaciae (Hemiptera: Psyllidae). - Ann. Entomol. Soc. Am. 107: 445-452.

Kavallieratos N.G., Stathas G.J., Athanassiou C.G. \& PapadouLIS G.T. 2002: Dittrichia viscosa and Rubus ulmifolius as reservoirs of aphid parasitoids (Hymenoptera: Aphelinidae) and the role of certain coccinellid species. - Phytoparasitica $\mathbf{3 0}$ : 231-242.

Kontodimas D.C. \& Stathas G.J. 2005: Phenology, fecundity and life table parameters of the predator Hippodamia variegata reared on Dysaphis crataegi. — BioControl 50: 223-233.

Koohpayezadeh N. \& Mossadegh M.S. 1991: Some of the ladybirds (Coccinellidae) fauna of Kerman province. Proceeding 
of the 10th Plant Protection Congress of Iran, 1-5 September 1991, Kerman, Iran. p. 64.

Kostal V. \& Simek P. 2000: Overwintering strategy in Pyrrhocoris apterus (Heteroptera): the relations between life-cycle, chill tolerance and physiological adjustments. - J. Insect Physiol. 46: $1321-1329$.

LEOPOLD R.A. 2007: Colony maintenance and mass-rearing: using cold storage technology for extending the shelf-life of insects. In Vreysen M.J.B., Robinson A.S. \& Hendrichs J. (eds): Area-Wide Control of Insect Pests. Springer, Dordrecht, pp. 149-162.

Loch A. 2004: New ladybird beetle in Australian vineyards. Austral. N. Z. Grapegr. Winem. 482: 20-23.

Liu Z., Gong P., Wu K., Wei W., Sun J. \& Li D. 2007: Effects of larval host plants on over-wintering preparedness and survival of the cotton bollworm, Helicoverpa armigera (Hübner) (Lepidoptera: Noctuidae). - J. Insect Physiol. 53: 1016-1026.

McDonald R.C. \& KoK L.T. 1990: Post refrigeration viability of Pteromalus puparum (Hymenoptera: Pteromalidae) prepupae within host chrysalids. - J. Entomol. Sci. 25: 409-413.

Nedved O. 1998: Modelling the relationship between cold injury and accumulated degree days in terrestrial arthropods. CryoLetters 19: 267-274.

OBRYCKI J.J. \& ORR C.J. 1990: Suitability of three prey species for Nearctic populations of Coccinella septempunctata, Hippodamia variegata and Propylea quatuordecimpunctata (Coleoptera: Coccinellidae). - J. Econ. Entomol. 83: 1292-1297.

ÖzGÖKÇE M.S., Atlihan R. \& Karaca I. 2006: The life table of Cryptolaemus montrouzieri Mulsant (Coleoptera: Coccinellidae) after different storage periods. - J. Food Agric. Environ. 4: $282-287$.

Pitcher S.A., Hoffmann M.P., Gardner J., Wright M.G. \& Kuhar T.P. 2002: Cold storage of Trichogramma ostriniae reared on Sitotroga cerealella eggs. - BioControl 47: 525-535.
R Development Core Team 2008: $R$ : A Language and Environment for Statistical Computing. R Foundation for Statistical Computing, Vienna.

Renault D., Hance T., Vannier G. \& Vernon P. 2003: Is body size an influential parameter in determining the duration of survival at low temperatures in Alphitobius diaperinus Panzer (Coleoptera: Tenebrionidae)? - J. Zool. 259: 381-388.

Renault D., Nedved O., Hervant F. \& Vernon P. 2004: The importance of fluctuating thermal regimes for repairing chill injuries in the tropical beetle Alphitobius diaperinus (Coleoptera: Tenebrionidae) during exposure to low temperature. Physiol. Entomol. 29: 139-145.

Rinehart J.P., Yocum G.D., Kemp W.P. \& Greenlee K.J. 2013: A fluctuating thermal regime improves long-term survival of quiescent prepupal Megachile rotundata (Hymenoptera: Megachilidae). - Apic. Soc. Insects 106: 1081-1088.

RuAN C.C., Du W.M., Wang X.M., Zhang J.J. \& ZANG L.S. 2012: Effect of long-term cold storage on the fitness of pre-wintering Harmonia axyridis (Pallas). - BioControl 57: 95-102.

TIBCO Software Inc. 2017: Statistica (Data Analysis Software System), Ver. 13. URL: http://www.statsoft.com/Products/STATISTICA-Features.

Venkatesan T., Singh S.P. \& Jalali S.K. 2000: Effect of cold storage on cocoons of Goniozus nephantidis Muesebeck (Hymenoptera: Bethylidae) stored for varying periods at different temperature regimes. - J. Entomol. Res. 24: 43-47.

Yaghmaee F. \& Kharazi Pakdel A. 1995: A faunistic survey of Coccinellids in Mashhad region. Proceeding of the 12th Plant Protection Congress of Iran, 2-7 September 1995, Karadj, Iran. p. 307.

Received March 1, 2018; revised and accepted December 12, 2018 Published online January 10, 2019 